\title{
Optimizing Power Allocation in a Cellular DS/FFH-CDMA System under Rayleigh Fading
}

\author{
P. VARZAKAS \\ Technological Educational Institute of Lamia, Department of Electronics \\ GR-35 100, Lamia, GREECE
}

\begin{abstract}
The optimization between the average received power and the theoretically achievable average channel capacity per user (in the Shannon sense) of a hybrid directsequence/ fast frequency hopping code-division multiple-access (DS/FFHCDMA) cellular system, when operating in a Rayleigh fading environment, is examined. The theoretical analysis leads to a novel-closed form expression for the optimal average received power value based on the maximization of the achieved spectral efficiency, estimated in terms of the available average channel capacity per user. Finally, respective numerical results are presented, which will be useful for the initial practical design of a DS/FFH-CDMA cellular system when operating in a Rayleigh fading environment.
\end{abstract}

Keywords: Hybrid CDMA systems, Power allocation, Cellular systems, Rayleigh fading.

Received: June 13, 2021. Revised: November 25, 2021. Accepted: December 12, 2021. Published: December 31, 2021.

\section{Introduction}

Hybrid systems are attractive because they can combine the advantages of both Direct Sequence (DS) and Frequency Hopping (FH) systems while avoiding some of their advantages. A hybrid DS/FFH-CDMA system can combine the anti-multipath effectiveness of DS system with the good antipartial-band-jamming and the good antinear-far problem features of FH system, [1]. Although, in general, in cellular networking, the hybrid DS/FFH-CDMA technique is not the standard technique remains an interesting technique for a number of reasons. Then, in a non-cellular or wireless local environment, where we have point-to-point communication without using a base station, this is a more flexible and cheaper method than the cellular approach. Because of the absence of base stations power control, playing a key role in reducing the near-far effect is no longer possible. FFH is therefore used to beat the near-far effect. On the other hand there is still DS with its well-known advantages: CDMA, jamming rejection, fading rejection and security.

Following the method and the hybrid system described firstly in [1], here, the spectral efficiency of a DS/FFHCDMA cellular system is evaluated in terms of each user's achievable average channel capacity. The channel capacity expression, establishes an upper bound limit for reliable information transmission over a bandlimited additive white Gaussian noise (AWGN) environment. When the channel side information (CSI) is not available at the transmitter, the source data is transmitted at a constant rate. Since no CSI is available at the transmitter, data transmission takes place over all fading states including deep fades where the data is lost and hence the effective channel capacity is significantly reduced. In cellular mobile radio, where signal fading is a considerable capacity degradation factor, channel capacity can be estimated in an average sense and used as a figure of merit for system's operation. This average channel capacity formula would indeed provide the true channel capacity, if channel side information were available at the receiver, [2]. It must be noticed, that the following analysis does not solve the problem of the capacity region, i.e., the set of information rates at which simultaneously reliable communication of the messages of each user is possible.
The final equation, theoretically derived, to the author's best knowledge, is the first time such expression has been exposed, thus avoiding complex algorithms or lengthy simulations. A comparison of the theoretical results derived here, with alternative methodologies described previously in literature, is not possible because these methodologies assume specific conditions for the system's operation and no one of these considers the case of the maximization of the available average channel capacity per user, [3-7]. Hence, a novel-closed form expression for the optimal average received power, in a Rayleigh fading environment, with respect to the maximization of the achieved spectral efficiency, estimated in terms of the available average channel capacity per user, is derived and respective numerical results are presented. The final expression can be very useful for the practical design of a DS/FFH-CDMA cellular system, specifically in the power control algorithm applied and for an initial quantitative analysis.

The remainder of this paper is organized as follows. Section II describes the system's model applied in the analysis and the operation of the considered hybrid DS/FFH-CDMA cellular system in an ideal non-fading AWGN and a Rayleigh fading environment. Numerical results and graphs are presented and discussed in section III. Final conclusions are outlined in the last section.

\section{System's Model and Optimal Received[3 RZHUIOD5 D OHJ ) DGQJL( QMIRQP HQW}

We consider a cellular DS/FFH-CDMA system where it is assumed that accommodates $\mathrm{K}$ of users per cell, in contrast to a variable allocation of users, which is governed by a birth-death process, implying a dynamic channel capacity model, and the users within each cell can be approximately orthogonalized, [8]. This is accomplished by choosing hopping sequences (shifts of the same basic sequence) that are orthogonal within the cells. In addition, hopping sequences need be assigned for minimum inter-cell correlation, meaning that any two users in adjacent cochannel cells interfere only at one hop during the period of the hopping sequence, [9]. However, the theoretical results 
derived in the paper can be applied directly in a DS/SFHCDMA system, with available number of users per cell, considering that the number of users per cell $\mathrm{K}$ represents the mean value of users per each cell.

Then, the original transmitted signal is only corrupted by AWGN and co-channel interference (CCI) power. During each frequency hop, a DS signal is transmitted in the form of a spread signal with bandwidth $\mathrm{W}_{\mathrm{ds}}=\mathrm{G}_{\mathrm{p}} \cdot \mathrm{W}_{\mathrm{s}}$, where $\mathrm{G}_{\mathrm{p}}$ is the processing gain applied and $\mathrm{W}_{\mathrm{s}}$ is the signal bandwidth. The totally allocated system's bandwidth $\mathrm{W}_{\mathrm{t}}$ is equal to:

$$
\mathrm{W}_{\mathrm{t}}=\mathrm{M} \cdot \mathrm{W}_{\mathrm{ds}}=\mathrm{M} \cdot \mathrm{G}_{\mathrm{p}} \cdot \mathrm{W}_{\mathrm{s}}
$$

where $M(M>1)$ is the number of hops per transmitted bit. In addition, we consider the CCI power resulting only from the first tier of the DS/FFH-CDMA cellular system assuming a cell cluster size equal to twelve and where all base stations' and mobile units' antennas are assumed omnidirectional. Thus, the channel capacity required for error-less transmission of a signal of bandwidth $\mathrm{W}_{\mathrm{ds}}$ will be given by the Shannon-Hartley theorem, [10]:

$$
\mathrm{C}_{i, \mathrm{DS} / \mathrm{FFH}}=\mathrm{W}_{\mathrm{ds}} \cdot \log _{2}\left(1+\mathrm{S}_{i, \mathrm{DS} / \mathrm{FFH}}\right)
$$

where $\mathrm{S}_{i, \mathrm{DS} / \mathrm{FFH}}, \quad i=[1, . ., 12 \mathrm{~K}]$, is the average signal-tointerference plus noise ratio (SINR) received at the $i$-th user as it reaches the boundary of a cell (i.e. the worst case of operation). Assuming that in the downlink all mobile units of a certain cell will receive equal average signal power from their cell site when appropriate power control scheme is applied, [11], then, for a fourth power law path loss, the average received signal power $\mathrm{P}_{\mathrm{r}}$ at the distance $\mathrm{r}$ by the $i$-th user, $i=[1, . ., 12 \mathrm{~K}]$, will be:

$$
\mathrm{P}_{\mathrm{r}}=\alpha \cdot \mathrm{r}^{-4}
$$

where $\alpha$ is a constant factor, [11]. Therefore, the SINR received by the mobile unit as it reaches the boundary of a cell, $\mathrm{S}_{i, \mathrm{DS} / \mathrm{FFH}}$, can readily be determined by considering the average CCI power resulting from the totally $11 \mathrm{~K} \mathrm{co-}$ channel interfering users: $2 \mathrm{~K}, 3 \mathrm{~K}$ and $6 \mathrm{~K}$, respectively, located at distances R, 2R and 2.633R, as follows, [11,12], i.e.:

$$
\begin{aligned}
& \mathrm{S}_{i, \mathrm{DS} / \mathrm{FFH}}= \\
& =\frac{\mathrm{P}_{\mathrm{r}}^{\prime}}{\mathrm{N}_{0} \cdot \mathrm{W}_{\mathrm{ds}}+\mathrm{P}_{\mathrm{h}} \cdot\left[2 \mathrm{~K} \cdot \alpha \cdot \mathrm{R}^{-4}+3 \mathrm{~K} \cdot \alpha \cdot(2 \mathrm{R})^{-4}+6 \mathrm{~K} \cdot \alpha \cdot(2.633 \mathrm{R})^{4}\right] \cdot \frac{1}{\mathrm{M}}}=(4) \\
& =\frac{\frac{\mathrm{P}_{\mathrm{r}}}{\mathrm{M}}}{\mathrm{N}_{0} \cdot \mathrm{W}_{\mathrm{ds}}+\mathrm{P}_{\mathrm{h}} \cdot(2.3123 \mathrm{~K}) \cdot \frac{\mathrm{P}_{\mathrm{r}}}{\mathrm{M}}}
\end{aligned}
$$

since, for a FFH transmission scheme, the CCI power, as seen by a desired signal, originates, on the average, from $1 / \mathrm{M}$ of the co-channel users, [13], and $\mathrm{P}_{\mathrm{r}}^{\prime}$ is the average received signal power by the mobile unit as it reaches the boundary of a cell and $\mathrm{N}_{0}$ is the noise power spectral density of the AWGN. However, it must be noted that (4) does not take into account the voice activity cycle, sector-reuse parameterization, lognormal variations and a random location model for the users' positions, as required in describing real commercial systems. Furthermore, CCI is considered as Gaussian distributed interference even for small values of the number of system's users, [14,15]. In eq.(4), $\mathrm{P}_{\mathrm{r}}^{\prime}$ is the user's average received signal power, in each of the $\mathrm{M}$ frequencies, being equal to:

$$
\mathrm{P}_{\mathrm{r}}^{\prime}=\frac{\mathrm{P}_{\mathrm{r}}}{\mathrm{M}}
$$

assuming that, in the FFH case, the totally transmitted signal power is equally shared, by hopping, among the $\mathrm{M}$ different carrier frequencies. In eq.(4), $\mathrm{P}_{\mathrm{h}}$ is the probability of hit, for the FFH case, approximated by:

$$
\mathrm{P}_{\mathrm{h}} \cong \frac{1}{\mathrm{M}}
$$

Thus, eq.(4) can be rewritten in the form:

$$
\mathrm{S}_{i, \mathrm{DS} / \mathrm{FFH}}=\frac{\mathrm{S}}{\mathrm{G}_{\mathrm{p}} \cdot \mathrm{M}+\frac{1}{\mathrm{M}} \cdot(2.3123 \cdot \mathrm{K}) \cdot \mathrm{S}}
$$

where $S=\left(P_{r} / N\right)$ is the average received signal-to-noise ratio (SNR) over signal bandwidth $\mathrm{W}_{\mathrm{s}}$ and $\mathrm{N}=\mathrm{N}_{0} \cdot \mathrm{W}_{\mathrm{s}}$ is the AWGN power over signal bandwidth $\mathrm{W}_{\mathrm{s}}$.

Assuming that the physical channel of bandwidth $\mathrm{W}_{\mathrm{ds}}$ is greater than the coherence bandwidth $\mathrm{W}_{\text {coh }}$ of the Rayleigh fading channel, the maximum number $\mathrm{M}_{\mathrm{ds}}$ of uncorrelated resolvable paths is approximated by, [16],:

$$
\mathrm{M}_{\mathrm{ds}}=\left[\mathrm{W}_{\mathrm{ds}} \cdot \Delta\right]+1 \approx\left(\mathrm{G}_{\mathrm{p}} \cdot \mathrm{W}_{\mathrm{s}} \cdot \Delta\right)+1
$$

where $\Delta$ is the maximum delay spread of the fading channel and [.] returns the largest integer less than, or equal to, its argument. Compared to DS transmission, where it can be said that the diversity effect is gained in parallel, the diversity in FFH transmission is achieved sequentially. Hence, a M hops per transmitted bit FFH system, can be seen as equivalent to an $\mathrm{M}$-branch maximal-ratio combining (MRC) space diversity system, [17]. Therefore, the average channel capacity per user $\left\langle\mathrm{C}_{i}\right\rangle_{\mathrm{DS} / \mathrm{FFH} \text {,Rayleigh, normalized over }}$ the total system's bandwidth $\mathrm{W}_{\mathrm{t}}$, is given by:

$$
\begin{aligned}
& \frac{\left\langle\mathrm{C}_{i}\right\rangle_{\mathrm{DS} / \mathrm{FFH}, \text { Rayleigh }}}{\mathrm{W}_{\mathrm{t}}}=\frac{\left\langle\mathrm{C}_{i}\right\rangle_{\mathrm{DS} / \mathrm{FFH}, \text { Rayleigh }}}{\mathrm{M} \cdot \mathrm{W}_{\mathrm{ds}}}= \\
& =\int_{0}^{\infty} \log _{2}(1+\gamma) \cdot \frac{(\gamma)^{\mathrm{M}-1}}{(\mathrm{M}-1) !\left(\mathrm{S}_{i, \mathrm{DS} / \mathrm{FFH}}\right)^{\mathrm{M}}} \cdot \exp \left(-\frac{\gamma}{\mathrm{S}_{i, \mathrm{DS} / \mathrm{FFH}}}\right) \cdot \mathrm{d} \gamma
\end{aligned}
$$

where $\langle$.$\rangle indicates average value and S_{i, \mathrm{DS} / \mathrm{FFH}}=\langle\gamma\rangle$, given by eq.(7), is the average received SINR in each of the M frequencies where the DS signal is transmitted. Furthermore, if path-diversity reception, provided by a MRC RAKE receiver, is also applied to the DS/FFHCDMA system, then additional diversity will be achieved. Hence, assuming that the multipath intensity profile (MIP) has equal path strengths on the average, the SINR after pathdiversity applied, in each of the $M$ frequencies, $S_{i, p t, D S / F F H}$ will be given by, [18],

$$
\begin{aligned}
& \mathrm{S}_{i, \mathrm{pt} \mathrm{DS} / \mathrm{FFH}}=\mathrm{M}_{\mathrm{ds}} \cdot \mathrm{S}_{i, \mathrm{DS} / \mathrm{FFH}}= \\
& =\mathrm{M}_{\mathrm{ds}} \cdot \frac{\mathrm{S}}{\mathrm{G}_{\mathrm{p}} \cdot \mathrm{M}+\frac{1}{\mathrm{M}} \cdot(2.3123 \mathrm{~K}) \cdot \mathrm{S}}=\mathrm{M}_{\mathrm{ds}} \cdot \frac{\mathrm{S}}{\frac{\mathrm{W}_{\mathrm{t}}}{\mathrm{W}_{\mathrm{s}}}+\frac{1}{\mathrm{M}} \cdot(2.3123 \mathrm{~K}) \cdot \mathrm{S}}
\end{aligned}
$$

where $S_{i, \mathrm{DS} / \mathrm{FFH}}=\langle\gamma\rangle$ is the average received SINR in each of the $\mathrm{M}$ frequencies in a Rayleigh fading channel (the 
suffice 'pt' refers to the path-diversity reception applied). Applying directly eq.(10) to eq.(9), $\left\langle\mathrm{C}_{i}\right\rangle_{\mathrm{DS} / \mathrm{FFH} \text {,Rayleigh, }}$ normalized over the total system's bandwidth $\mathrm{W}_{\mathrm{t}}$, is rewritten as:

$$
\begin{aligned}
& \frac{\left\langle\mathrm{C}_{i}\right\rangle_{\mathrm{DS} / \mathrm{FFH}, \text { Rayleigh }}}{\mathrm{W}_{\mathrm{t}}}=\frac{\left\langle\mathrm{C}_{i}\right\rangle_{\mathrm{DS} / \mathrm{FFH}, \text { Rayleigh }}}{\mathrm{M} \cdot \mathrm{W}_{\mathrm{ds}}}= \\
= & \int_{0}^{\infty} \log _{2}(1+\gamma) \cdot \frac{(\gamma)^{\mathrm{M}-1}}{(\mathrm{M}-1) !\left(\mathrm{S}_{i, \mathrm{pt}, \mathrm{DS} / \mathrm{FFH}}\right)^{\mathrm{M}}} \cdot \exp \left(-\frac{\gamma}{\mathrm{S}_{i, \mathrm{pt}, \mathrm{DS} / \mathrm{FFH}}}\right) \cdot \mathrm{d} \gamma
\end{aligned}
$$

The problem of maximization of the normalized average channel capacity per user, can be stated as follows:

$$
\max \int_{0}^{\infty} \log _{2}(1+\gamma) \cdot \frac{(\gamma)^{\mathrm{M}-1}}{(\mathrm{M}-1) !\left(\mathrm{S}_{i, \mathrm{pt}, \mathrm{DS} / \mathrm{FFH}}\right)^{\mathrm{M}}} \cdot \exp \left(-\frac{\gamma}{\mathrm{S}_{i, \mathrm{pt}, \mathrm{DS} / \mathrm{FFH}}}\right) \cdot \mathrm{d} \gamma
$$

The combined average spread SINR after diversity reception i.e. $S_{i, \mathrm{pt}, \mathrm{DS} / \mathrm{FFH}} \cdot \mathrm{M}_{\mathrm{ds}}$, that maximizes eq.(12), equals to $6 \mathrm{~dB}$, [19], i.e.,

$$
\begin{aligned}
& \mathrm{S}_{i, \mathrm{pt}, \mathrm{DS} / \mathrm{FFH}} \cdot \mathrm{M}_{\mathrm{ds}}=\mathrm{M}_{\mathrm{ds}}^{2} \cdot \mathrm{S}_{i, \mathrm{DS} / \mathrm{FFH}}= \\
& =\mathrm{M}_{\mathrm{ds}}^{2} \cdot \frac{\mathrm{S}}{\frac{\mathrm{W}_{\mathrm{t}}}{\mathrm{W}_{\mathrm{s}}}+\frac{1}{\mathrm{M}} \cdot(2.3123 \cdot \mathrm{K}) \cdot \mathrm{S}}=10^{0.6}
\end{aligned}
$$

applying directly eq.(10). The eq.(13) can be rewritten as:

$$
\mathrm{M}_{\mathrm{ds}}{ }^{2} \cdot \frac{\frac{\mathrm{P}_{\mathrm{r}}}{\mathrm{N}_{0} \cdot \mathrm{W}_{\mathrm{s}}}}{\mathrm{G}_{\mathrm{p}} \cdot \mathrm{M}+\frac{1}{\mathrm{M}} \cdot(2.3123 \cdot \mathrm{K}) \cdot \frac{\mathrm{P}_{\mathrm{r}}}{\mathrm{N}_{0} \cdot \mathrm{W}_{\mathrm{s}}}}=10^{0.6}
$$

Then, the optimal received power $\mathrm{P}_{\mathrm{r}, \mathrm{op}}$ (the new suffice 'op' refers to the optimal value) can be found directly from eq.(14), as following i.e.:

$$
\mathrm{P}_{\mathrm{r}, \mathrm{op}}=\frac{3.9 \cdot \mathrm{M}^{2} \cdot \mathrm{N}_{0} \cdot \mathrm{W}_{\mathrm{s}} \cdot \mathrm{G}_{\mathrm{p}}}{\mathrm{M} \cdot \mathrm{M}_{\mathrm{ds}}^{2}-9.2 \cdot \mathrm{K}}
$$

\section{Numerical Results}

The optimal received power $\mathrm{P}_{\mathrm{r}, \mathrm{op}}$ (expressed in Watt $(\mathrm{W})$ ), given by eq.(15), is plotted in Figure 1 as function of the number of users per cell $\mathrm{K}$, where the following values are assumed: (i) totally constant allocated system's bandwidth: $\mathrm{W}_{\mathrm{t}}=10 \mathrm{MHz}$, (ii) signal bandwidth: $\mathrm{W}_{\mathrm{s}}=30 \mathrm{KHz}$, (iii) number of hops per transmitted bit: $\mathrm{M}=5$, (iv) total multipath spread of the urban Rayleigh fading channel: $\Delta=3 \mu \mathrm{sec}$.

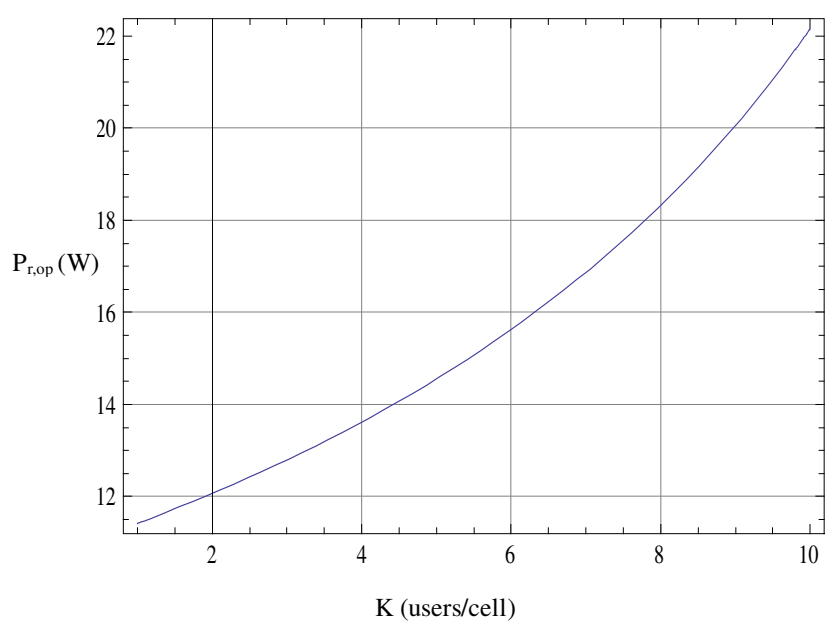

Figure 1. Optimal received power $\mathrm{P}_{\mathrm{r}, \mathrm{p}}$ in a DS/FFH-CDMA cellular system versus the number $\mathrm{K}$ of users per cell in a Rayleigh fading environment.

As it can be seen directly from Figure 1, the required value of optimal received power $\mathrm{P}_{\mathrm{r}, \mathrm{op}}$ is increased as the number of users per cell $\mathrm{K}$ is increased, indicating that when the number of users per cell increases, and consequently the CCI power increases respectively, the required optimal received power $\mathrm{P}_{\mathrm{r}, \mathrm{op}}$ must be increased respectively in order to minimize the impact of the CCI power on the system's performance.

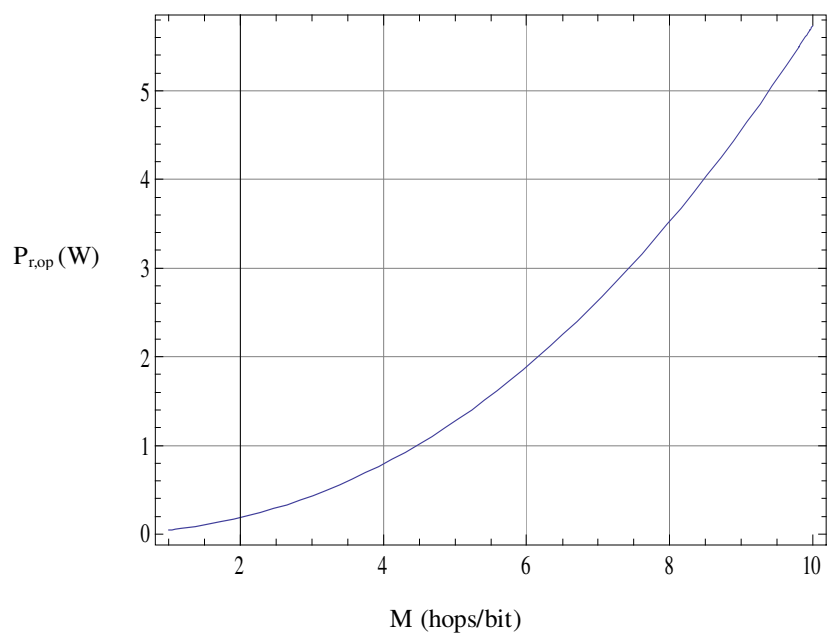

Figure 2. Optimal received power $\mathrm{P}_{\mathrm{r}, \mathrm{op}}$ in a DS/FFH-CDMA cellular system versus the number $\mathrm{M}$ of hops per transmitted bit in a Rayleigh fading environment.

In addition in Figure 2, the optimal received power $\mathrm{P}_{\mathrm{r}, \mathrm{op}}$, (expressed in Watt (W)), is plotted as function of the number $M$ of hops per transmitted bit, for: $S=30 \mathrm{~dB}$, $\mathrm{W}_{\mathrm{t}}=10 \mathrm{MHz}, \mathrm{W}_{\mathrm{s}}=30 \mathrm{KHz}, \Delta=3 \mu \mathrm{sec}$ and $\mathrm{K}=10$ users per cell as an indicative value (in real cellular systems the actual number $\mathrm{K}$ of users per cell is of the order of 50). As it can be seen directly from Figure 3, the required value of optimal received power $P_{r, o p}$ is increased as the number $M$ of hops per transmitted bit increased, indicating that although an increased value of number $M$ of hops per transmitted bit provides increased inherent diversity potential, the CCI power is still sufficient and then, an increased value of the 
received power $\mathrm{P}_{\mathrm{r}, \mathrm{op}}$ is needed finally, in order to minimize the effect of the CCI in the system's performance.

\section{Conclusions}

In this paper, we estimate the optimal average received power of a cellular DS/FFH-CDMA system when operating in a Rayleigh fading environment, which maximizes the achieved spectral efficiency. Spectral efficiency is expressed in terms of the average channel capacity available to each user, when additional path-diversity reception is applied. It is derived, without applying complex theoretical algorithms or lengthy simulations, a general expression, which relates the optimal average received power with all system's parameters. However, it must be noticed that, similar expression has been recently derived by the author in [20], but concerning the optimization of the processing gain applied. The final expression can be useful for the initial practical design of a DS/FFH-CDMA cellular system in a Rayleigh fading environment and for the power control scheme applied but a simulation process or an experimental comparison with other methods must be described analytically, in a future paper, in order to compare with the theoretical results derived in this paper.

\section{$5 \mathrm{HH}$ HFH}

[1] P.Varzakas and G.S.Tombras, "Spectral efficiency for a hybrid DS/FH CDMA system in cellular mobile radio", IEEE Trans. on Veh. Technology, vol.50, no.6, pp.1321-1327, Nov.2001.

[2] A.J.Goldsmith and P.Varaiya, "Capacity of fading channels with channel side information", IEEE Trans. on Inform. Theory, vol.43, no.6, pp.1986-1992, Nov.1997.

[3] S.Songsong and W.A.Krzymien, "Hybrid ARQ and optimal signal-tointerference ratio assignment for high-quality data transmission in DS-CDMA", European Trans. on Telecommunications, vol.12, no.1, pp. 19-29, 2001

[4] S.Kandukuri and S.Boyd, "Optimal power control in interferencelimited fading wireless channels with outage probability specifications", IEEE Trans. on Wireless Communications, vol.1, no.1, pp.46-55, 2002.

[5] M.Xiao, N.Shroff and E.Ching, "A utility-based power-control scheme in wireless cellular systems", IEEE/ACM Trans. on Networking, vol.11, pp.210-221, 2003.

[6] H.Boche and S.Stanczak, "Convexity of some feasible QoS regions and asymptotic behavior of the minimum total power in CDMA systems", IEEE Trans. on Communications, vol.52, no.12, pp.21902197, 2004.

[7] T.Alpcan, T.Basar, R.Sricant and E.Altman, "CDMA uplink power control as a noncooperative game", Wireless Networks, vol.8, pp.659669, 2002.

[8] N.Livneh, R.Meidan, M.Ritz and G.Silbershatz, "Frequency hopping CDMA for cellular radio", Proc. of the International Commsphere Symposium, Herzilya, Israel, pp.10.5.1-10.5.6, Dec. 1991.

[9] A.Lempel and H.Greenberger, "Families of sequences with optimal hamming correlation properties", IEEE Trans. Inform. Theory, vol. IT-1, pp.90-94, Jan.1974.

[10] C.E.Shannon, "Communication in the presence of noise", Proc. of IRE, vol.37, pp.10-21, Jan.1949.

[11] M.K.Simon and M.S.Alouini, 'Digital Communication over Fading Channels: A Unified Approach to Performance Analysis', Wiley: New York, 2000.

[12] W.C.Y.Lee, 'Mobile Communications Design Fundamentals', $2^{\text {nd }}$ ed. New York: Wiley, 1993.

[13] C.D'Amours and A.Yongacoglu, "Hybrid DS/FH-CDMA system employing MT-FSK modulation for mobile radio", in Proc. PIMRC'95, Toronto, Canada, pp.164-168, Sept. 1995.
[14] K.S.Gilhousen, I.M.Jacobs, R.Padovani, A.Viterbi, L.A.Weaver, and C.E.Wheatley, "On the capacity of a cellular CDMA system", IEEE Trans. on Veh. Technol., vol. 40, pp.303-312, May 1991.

[15] E.A.Geraniotis, "Coherent hybrid DS-SFH spread-spectrum multiple access communications", IEEE J. Select. Areas Commun., vol. SAC3, Sept. 1985.

[16] J.G.Proakis, and M.Salehi, 'Digital Communications', 5 ${ }^{\text {rd }}$ Edit., McGraw-Hill, 2008.

[17] R.Kohno, R.Meidan and L.B.Milstein, "Spread spectrum access methods for wireless communications", IEEE Commun. Mag., pp.5867, Jan.1995.

[18] Y.Murata, R.Esmailzadeh, K.Takakusaki, E.Sourour and M.Nakagawa, "Path diversity for FFH/PSK spread-spectrum communication systems", IEEE J. Select. Areas Commun., vol.12, no.5, pp.970-975, June 1994.

[19] F.Lazarakis, G.S.Tombras and K.Dangakis, "Average Channel Capacity in a Mobile Radio Environment with Rician Statistics", IEICE Trans. on Commun., vol. E-77B, no.7, pp.971-977, July 1994.

[20] P.Varzakas, "On the optimum processing gain for a hybrid DS/FFHCDMA cellular system over Rayleigh fading channels", International Journal of Communication Systems, vol. 24, no.7, pp.902-910, July 2011.

\section{Creative Commons Attribution License 4.0 (Attribution 4.0 International, CC BY 4.0)}

This article is published under the terms of the Creative Commons Attribution License 4.0 https://creativecommons.org/licenses/by/4.0/deed.en_US 